\title{
Design and optimization of an automatic hydraulic steer-by-wire system for an agricultural chassis
}

\author{
Yinhao J in ${ }^{1}$, Yanwei Yuan ${ }^{2}$, Licheng Zhu², Decheng Wang ${ }^{1}$, Bo Zhao ${ }^{2}$, Xianfa Fang ${ }^{1,2^{*}}$ \\ (1. College of Engineering, China Agricultural University, Beijing 100083, China; \\ 2. State Key Laboratory of Soil-Plant-Machine System Technology, Chinese Academy of Agricultural Mechanization Sciences, \\ Beijing 100083, China)
}

\begin{abstract}
To meet the requirements of fast steering at low vehicle speed and slow steering at high vehicle speed, the automatic steering of agricultural chassis must control both the wheel steering angle and the steering angle's angular speed. This study applied hydraulic steer-by-wire technology to the automatic steering control of agricultural chassis. First, the transmission mechanism of the designed steering system was optimized. According to the rule of least squares, aiming at the minimum sum of squares of errors between 10 ideal outer wheel angles and real outer wheel angles, the optimal solution of hole spacing on both sides of the steering hydraulic cylinder piston rod was $925 \mathrm{~mm}$. The outer wheel angle error of the optimized steering mechanism throughout the steering stroke was less than $0.15^{\circ}$. Additionally, a hydraulic steer-by-wire system was developed, and the parameters of its critical components were calculated. Then, the compound control strategy of the steering cylinder piston rod displacement and moving speed was formulated for this automatic steering system. The entire control system included a valve control signal calculation model, an initial velocity calculation model, a correction velocity calculation model, and an attenuation velocity calculation model, and the formulae of each model were deduced. Based on the optimized parameters and the developed control strategy, a simulation model was built in AMESim, and simulation results showed that the proposed control strategy could achieve simultaneous controls of piston rod displacement and speed at different vehicle speeds and loads. The horizontal and vertical displacements of the right wheel center were plotted for typical vehicle speeds and steering commands. The results of this study provided a new idea for the application of hydraulic steer-by-wire technology in the automatic steering of agricultural chassis.
\end{abstract}

Keywords: optimal design, steering mechanism, automatic steering, simulation analysis DOI: $10.25165 /$ j.ijabe.20221501.6755

Citation: Jin Y H, Yuan Y W, Zhu L C, Wang D C, Zhao B, Fang X F. Design and optimization of an automatic hydraulic steer-by-wire system for an agricultural chassis. Int J Agric \& Biol Eng, 2022; 15(1): 132-138.

\section{Introduction}

With the rapid development of automatic control technology and navigation technology, the level of automation and intelligence of agricultural equipment is also improving. Automatic steering technology is a critical technology that is needed to achieve automatic navigation in agricultural machinery ${ }^{[1-4]}$. Electrohydraulic control steering systems typically have large output powers and fast response speeds, making them more suitable for applications in agricultural machinery ${ }^{[5-7]}$. Compared to other forms of electrohydraulic control steering systems, the hydraulic steer-by-wire system has more applicable advantages because it can change the steering ratio of its steering system ${ }^{[8-12]}$. A good steering system requires its control system to execute steering

\section{Received date: 2021-05-11 Accepted date: 2021-11-29}

Biographies: Yinhao Jin, $\mathrm{PhD}$ candidate, research interest: design and control of vehicle chassis, Email: jinyinhao@cau.edu.cn; Yanwei Yuan, PhD, Professor, research interest: application of computer and automation technology in agriculture, Email: yyw215@163.com; Licheng Zhu, Associate Professor, research interest: agricultural robotics, Email: zhulicheng@caams.org.cn; Decheng Wang, PhD, Professor, research interest: practaculture machine, Email: wdc@cau.edu.cn; Bo Zhao, PhD, Professor, research interest: variable-rate technology in precision agriculture, Email: zhaoboshi@126.com.

*Corresponding author: Xianfa Fang, PhD, Professor, research interest: agricultural mechanization. Chinese Academy of Agricultural Mechanization Sciences, P.O. Box 25, No.1 Beishatan, Dewai St, Beijing 100083, China. Tel: +86-10-64882658, Email: Fangxf@caams.org.cn. commands quickly and accurately, and requires a reasonable design of steering transmission mechanism parameters to reduce steering resistance torque and tire wear ${ }^{[13,14]}$. Thus, scholars have investigated automatic steering, steer-by-wire, and steering mechanism parameter optimization.

In the literature describing automatic steering technology, Ren et al. ${ }^{[15]}$ designed and installed an automatic steering actuator with a clutch shaft that did not change the original steering operation structure, and achieved remote control automatic steering of rice transplanters. Yin et al. ${ }^{[16,17]}$ installed an automatic steering system with a brushless DC motor as the power source on an original manual steering system, and made corresponding ground turning trajectories for different types of agricultural machinery vehicles. In the above literature, the agricultural chassis realizes the automatic steering function by refitting the original chassis.

In the literature describing steer-by-wire technology, $\mathrm{Lu}$ et al. ${ }^{[18,19]}$ used a dual-channel PID control method to control the extension and retraction of the piston rod of a hydraulic cylinder in different channels, which improved the control accuracy of the steering system. Zong et al. ${ }^{[20]}$ used yaw velocity gain and steering sensitivity as the design parameters of variable angle transmission ratio characteristics by analyzing related objective evaluation indices of handling. In the above literature, the application scenario of steer-by-wire technology is still traditional manned steering.

In the literature describing parameter optimization of the steering mechanism, Liu et al. ${ }^{[21]}$ optimized the mechanical 
parameters of a steering mechanism with an adjustable wheel track, taking the minimum track as the basic track, where the optimized steering mechanism can also meet the steering performance of other wheel tracks. Jiang et al. ${ }^{[22]}$ used multi-objective parameter optimization based on the orthogonal test, and the overall performance of the optimized steering mechanism was markedly improved. In the above literature, the parameters of each specific steering mechanism are optimized and good results are achieved.

In summary, the previous research did not apply the steer-by-wire technology to the automatic steering of agricultural chassis. In this study, the parameters of a front-wheel steering mechanism on an agricultural chassis are optimized, based on which the steering system load is calculated and the key components of the steering system are designed and selected. A steer-by-wire control system was designed; the joint control strategy of piston rod displacement and speed of the steering cylinder was formulated; the corresponding calculation model of the control module was deduced. The system simulation model was developed in AMESim to simulate the control accuracy of the system under different working conditions, and the results show that the developed control strategy achieves the joint control of wheel steering angle and steering angular velocity.

\section{Optimization of the steering mechanism}

Reasonable design of a steering transmission mechanism can improve steering performance, reduce the steering resistance moment, reduce tire wear, etc. The front-wheel steering mechanism designed in this paper is shown in Figure 1.

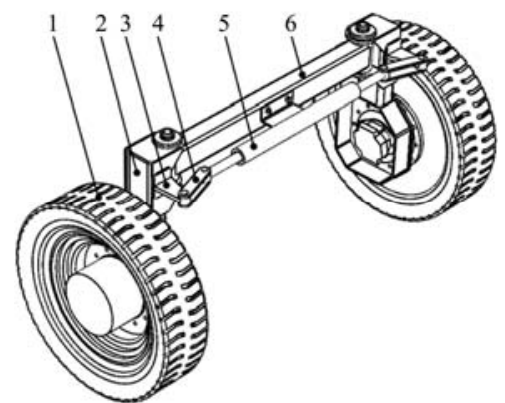

1. Wheel 2. Leg 3. Steering arm 4. Linkage 5. Steering hydraulic cylinder 6. Front axle

Figure 1 Steering transmission mechanism

The steering transmission mechanism is primarily composed of a steering hydraulic cylinder, two linkages, two steering arms, and a front axle. The cylinder of the steering hydraulic cylinder is fixed on the front axle, and the steering arm is fixed on the leg. One end of the piston rod head of the hydraulic cylinder is hinged with the linkage through the pin shaft, and the other end of the linkage is hinged with the steering arm. When the vehicle goes straight, the piston rod of the hydraulic cylinder is stationary, and the steering transmission mechanism is symmetrical. When steering, the hydraulic cylinder receives hydraulic oil from the steering hydraulic system and pushes the piston rod to move linearly. The linkage pushes the steering arm, leg, and wheel to move in a partial circle.

\subsection{Error analysis of the steering angle}

In an ideal state, the vehicle should satisfy the Ackerman steering principle when turning. In this study, the right turn of the wheel was taken as an example, as shown in Figure 2.

According to the Ackerman steering principle, there is an ideal angular relationship between the outer wheel and the inner wheel, as defined in Equations (1) and (2).

$$
\begin{gathered}
\cot \beta_{o}-\cot \alpha=\frac{W}{L} \\
\beta_{o}=\operatorname{arccot}\left(\cot \alpha+\frac{W}{L}\right)
\end{gathered}
$$

where, $\beta_{o}$ is the ideal steering angle of the outer wheel, $\left({ }^{\circ}\right) ; L$ is the wheelbase, $\mathrm{mm} ; W$ is the distance between the centerline of the left and right vertical axes and the ground intersection, $\mathrm{mm} ; \alpha$ and $\beta$ are the steering angles of the inner and outer wheels, respectively, $\left({ }^{\circ}\right)$. In this study, $L=2000 \mathrm{~mm}, W=1000 \mathrm{~mm}$, and the maximum steering angle of the inner wheel $\alpha_{\max }=30^{\circ}$.

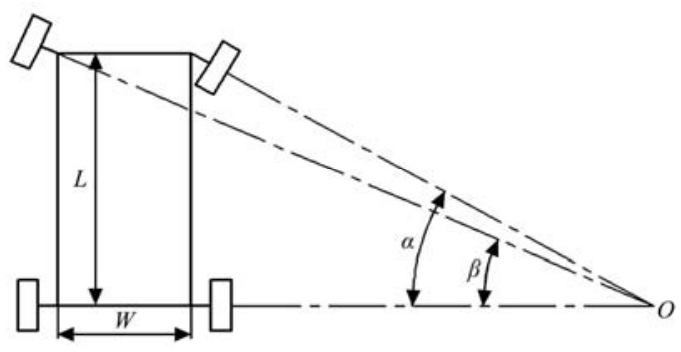

Note: $L$ is the wheelbase, $\mathrm{mm} ; W$ is the distance between the centerline of the left and right vertical axes and the ground intersection, $\mathrm{mm} ; \alpha$ and $\beta$ are the steering angles of the inner and outer wheels, respectively, $\left({ }^{\circ}\right)$. In this study, $L=2000$ $\mathrm{mm}, W=1000 \mathrm{~mm}$, and the maximum steering angle of the inner wheel $\alpha_{\max }=30^{\circ}$.

Figure 2 Schematic of Ackerman steering principle

Figure 3 shows the change in the steering transmission mechanism when the vehicle is turning. Considering the right turn of the wheel as an example, the solid line is the state when the vehicle is not turning, and the dotted line is the state after turning.

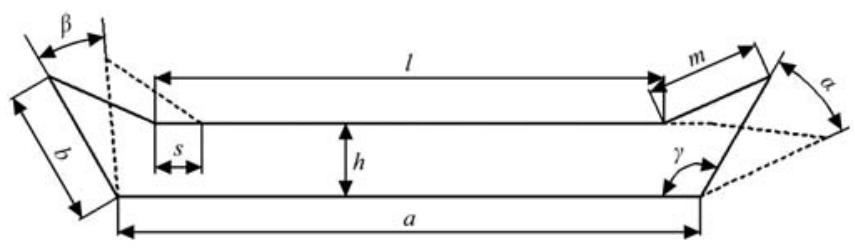

Note: $a$ is the distance between the left and right steering spindles of the front axle, $\mathrm{mm} ; b$ is the distance from the steering spindle to the center of the steering armhole, $\mathrm{mm} ; h$ is the vertical distance between the center axis of the steering hydraulic cylinder and the two steering spindles of the front axle, $\mathrm{mm} ; l$ is the distance between the left and right holes of the piston rod of the steering cylinder, $\mathrm{mm} ; m$ is the distance between the hole centers on both sides of the linkage, $\mathrm{mm}$; $s$ is the moving distance of the piston rod of the steering cylinder, mm; and $\gamma$ is the angle between the steering arm and the front axle when not steering. In this study, $a=1000 \mathrm{~mm}, b=220 \mathrm{~mm}, h=140 \mathrm{~mm}$, and $\gamma=120^{\circ}$.

Figure 3 Change in the transmission mechanism during steering

According to the geometric relationships shown in Figure 3, Equations (3)-(5) can be derived as follows:

$$
\begin{gathered}
m=\sqrt{\left[\frac{a}{2}+b \cos \left(\pi-\gamma \frac{\pi}{180}\right)-\frac{l}{2}\right]^{2}+\left[\left(b \sin \left(\pi-\gamma \frac{\pi}{180}\right)-h\right)\right]^{2}} \\
s=b \cos \left(\pi-\gamma \frac{\pi}{180}-\alpha \frac{\pi}{180}\right)+\frac{a-l}{2}- \\
\sqrt{m^{2}-\left[\left(b \sin \left(\pi-\gamma \frac{\pi}{180}-\alpha \frac{\pi}{180}\right)-h\right)\right]^{2}} \\
\beta=\gamma-\frac{180}{\pi} \arccos \frac{b^{2}+\left[\left(\frac{a-l}{2}\right)+s\right]^{2}+h^{2}-m^{2}}{2 b \sqrt{\left[\left(\frac{a-l}{2}\right)+s\right]^{2}+h^{2}}}- \\
\frac{180}{\pi} \arctan \frac{h}{\left(\frac{a-l}{2}\right)+s}
\end{gathered}
$$


where, $a$ is the distance between the left and right steering spindles of the front axle, $\mathrm{mm} ; b$ is the distance from the steering spindle to the center of the steering armhole, $\mathrm{mm} ; h$ is the vertical distance between the center axis of the steering hydraulic cylinder and the two steering spindles of the front axle, $\mathrm{mm} ; l$ is the distance between the left and right holes of the piston rod of the steering cylinder, $\mathrm{mm} ; m$ is the distance between the hole centers on both sides of the linkage, mm; $s$ is the moving distance of the piston rod of the steering cylinder, $\mathrm{mm} ; \gamma$ is the angle between the steering arm and the front axle when not steering. In this study, $a=$ $1000 \mathrm{~mm}, b=220 \mathrm{~mm}, h=140 \mathrm{~mm}$, and $\gamma=120^{\circ} ; \delta$ is the steering angle error of the outer wheel, as shown in Equation (6).

$$
\delta=\beta_{o}-\beta
$$

\subsection{Parameter optimization of the steering mechanism}

The preceding analysis showed that when the steering angle of the inner wheel $\alpha$ is known, there is only one unknown quantity $l$ in the steering transmission mechanism. The optimization of the steering mechanism parameters finds the optimal $l$ so that the change in the steering angle of the inner and outer wheels during the steering process is more in line with the Ackerman steering principle.

The optimization method used in this paper is the least square method, which seeks the best value of $l$ by solving the least square sum of $\delta$ for 10 steering angles of the inner wheel. The objective function and constraints are as follows:

$$
\begin{gathered}
\min \sum_{i=1}^{10} \delta_{i}^{2} \quad(i=1,2, \ldots, 10) \\
\text { s.t. }\left\{\begin{array}{c}
\delta_{i}=\beta_{0 i}-\beta_{i} \\
\alpha_{i}=3 i \\
500 \leq l \leq 1000,1 \in N^{*}
\end{array} \quad(i=1,2, \ldots, 10)\right.
\end{gathered}
$$

Input this objective function and constraints into Lingo, it shows that the optimal $l$ is $925 \mathrm{~mm}$. Detailed results are listed in Table 1.

Table 1 Steering angle of the inner and outer wheels when $l=925 \mathbf{m m}$

\begin{tabular}{ccccccccccc}
\hline$\alpha /\left(^{\circ}\right)$ & 3 & 6 & 9 & 12 & 15 & 18 & 21 & 24 \\
\hline$\beta_{o} /\left(^{\circ}\right)$ & 2.924 & 5.702 & 8.349 & 10.876 & 13.295 & 15.616 & 17.851 & 20.010 \\
$\beta /\left(^{\circ}\right)$ & 2.916 & 5.677 & 8.299 & 10.801 & 13.202 & 15.517 & 17.765 & 19.962 & 22.101 \\
$\delta /\left(^{\circ}\right)$ & 0.008 & 0.025 & 0.020 & 0.075 & 0.093 & 0.099 & 0.086 & 0.048 & -0.024 & -0.140 \\
\hline
\end{tabular}

The optimized steering mechanism is modeled in SolidWorks software, motion analysis was performed, and the corresponding change in the real outer wheel angle when the inner angle changes from $0^{\circ}-30^{\circ}$ were obtained, as shown in Figure 4.

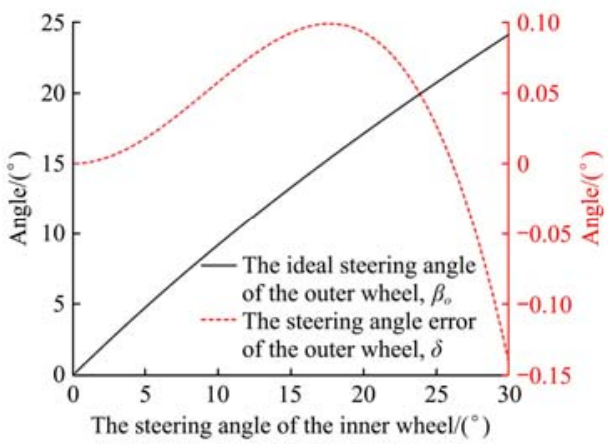

Figure 4 Relationship among $\alpha, \beta_{o}$, and $\delta$

Table 1 and Figure 4 show that throughout the steering process, the outer wheel steering angle error $\delta$ is always small, which indicates that the optimization result of $l=925 \mathrm{~mm}$ is feasible.

According to Equation (4), when the steering angle of the inner wheel $\alpha_{\max }=30^{\circ}$, the maximum distance $s_{\max }$ that the hydraulic cylinder piston rod can move from the neutral position to one side is $75.03 \mathrm{~mm}$. Here it is stipulated that $s>0$ when the steering cylinder piston rod is off to the right relative to the original position, and $s<0$ when the steering cylinder piston rod is off to the left relative to the original position. Figure 5 shows the relationship between the moving distance of the piston rod of the steering cylinder $s$ and the steering angle of the right wheel. When $s<0$, the angle is the outer wheel steering angle when turning left; when $s>0$, the angle is the inner wheel steering angle when turning right.

\subsection{Calculating steering hydraulic cylinder parameters}

Referring to the TABOREK formula, the calculation of the steering resistance moment is shown in Equation (8).

$$
M_{l}=0.05 \cdot G_{s} \cdot \frac{1}{1+\frac{e}{B}} \cdot \frac{B}{200} \cdot \frac{\mu_{s}}{0.7}
$$

where, $M_{l}$ is the steering torque, $\mathrm{N} \cdot \mathrm{m} ; G_{s}$ is the force on the front axle, $\mathrm{N} ; e$ is the kingpin offset, $\mathrm{mm}$; $B$ is the tire breadth, $\mathrm{mm}$; and $\mu_{s}$ is the friction coefficient. In this study, the weight of the vehicle is $1.8 \mathrm{t}$ at full load and $1.4 \mathrm{t}$ at no load, and the load on the front axle is half of the gravitational force of the entire vehicle; thus, $G_{s \max }=9000 \mathrm{~N}$ and $G_{s \min }=7000 \mathrm{~N} . \quad e=270 \mathrm{~mm}, B=200 \mathrm{~mm}$, and $\mu_{s}=0.8$.

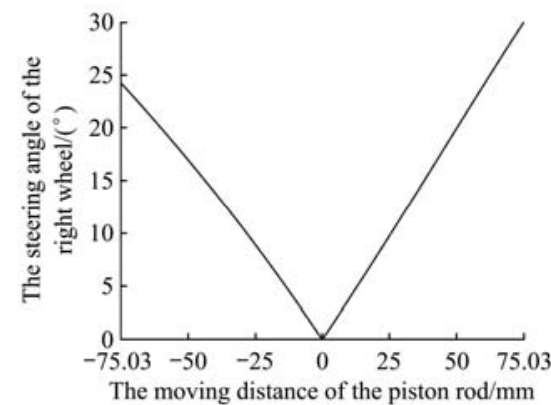

Figure 5 Relationship between the moving distance of the piston rod of the steering cylinder $s$ and the steering angle of the right wheel

The maximum steering resistance of the steering hydraulic cylinder is calculated by Equation (9).

$$
F_{\max }=\frac{M_{l \text { max }}}{r_{\min }}
$$

where, $r_{\min }$ is the minimum effective radius arm for steering cylinders, $\mathrm{m}$. In this study, $r_{\min }=0.195 \mathrm{~m}$.

According to Equations (8) and (9), $M_{l \max }=218.845 \mathrm{~N} \cdot \mathrm{m}$, and $F_{\max }=1122.282 \mathrm{~N}$.

The equation used to calculate the steering hydraulic cylinder piston diameter is shown in Equation (10).

$$
D_{1}=\sqrt{\frac{4 F_{\max }}{\pi \eta_{m} p\left(1-\varphi^{2}\right)}}
$$

where, $D_{1}$ is the piston diameter of the steering hydraulic cylinder, $\mathrm{m} ; \eta_{m}$ is the mechanical efficiency of the hydraulic cylinder; $p$ is the pressure of the oil inlet chamber of the hydraulic cylinder, MPa; $\varphi$ is the rod diameter ratio. Here, $\eta_{m}=0.85, p=2 \mathrm{MPa}$, and $\varphi=0.5$. 
After calculations are performed, and trade-offs are considered, the piston diameter of the hydraulic cylinder was set to $D=40 \mathrm{~mm}$ and the piston rod diameter was set to $d=20 \mathrm{~mm}$.

\section{Designing an automatic hydraulic steer-by-wire system}

\subsection{Hydraulic steer-by-wire system}

To fully exploit the steer-by-wire system with variable steering ratios and electronic control, hydraulic steer-by-wire technology is applied to automatic steering systems in agricultural chassis. The principle of this study is shown in Figure 6.

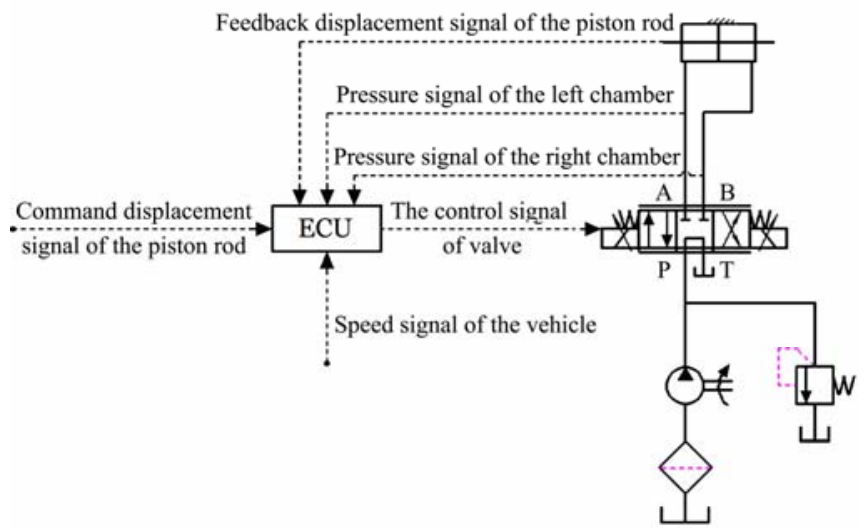

Figure 6 Hydraulic steer-by-wire system

The hydraulic steer-by-wire system primarily consists of a hydraulic pump, an ECU, a three-position four-way proportional directional valve, a double-piston rod double-acting hydraulic cylinder, etc. The hydraulic pump is the power element of this system that provides hydraulic oil to the hydraulic steering system. The ECU is the control element of this system that calculates the command signal and feedback signal according to a specific control algorithm and outputs the electronic control signal. The three-position four-way proportional-directional valve is a hydraulic amplifying element of this system that converts the electrical signal sent by the ECU into a mechanical displacement signal of the spool and amplifies the mechanical displacement signal into a high-power hydraulic signal. The double-piston rod double-acting hydraulic cylinder is the executive element of this system that drives the piston rod to move to complete the steering action. In this study, the pump outlet pressure is 20 bar; the steering cylinder piston diameter $\mathrm{D}=40 \mathrm{~mm}$; the piston rod diameter $\mathrm{d}=20 \mathrm{~mm}$; the cylinder stroke $S=150.06 \mathrm{~mm}$; and the proportional directional valve model is Rexroth L8581B2S1.

\subsection{Joint control of piston rod displacement/speed}

When the vehicle is turning at a low vehicle speed, the wheel should turn quickly (i.e., the piston rod of the steering cylinder should move quickly to complete the steering process as soon as possible). When turning at a high vehicle speed, the wheels should turn slowly (i.e., the moving speed of the piston rod of the steering cylinder should be slow) to prevent accidents. Therefore, the control system designed in this paper considers two aspects: 1) the control of the wheel steering angle after the completion of the steering process (i.e., the control of the piston rod displacement of the steering cylinder); and 2) the control of the wheel steering angular speed in the steering process (i.e., the control of the moving speed of the piston rod of the steering cylinder).

The joint control strategy of piston rod displacement and speed proposed in this study is shown in Figure 7. When steering, the commanded piston rod displacement signal is compared with the real feedback displacement signal. In the front and middle parts of the steering process, the expected piston rod speed is derived from the initial rod speed calculation model, which is related to the vehicle speed. When the real feedback displacement signal reaches the vicinity of the commanded piston rod displacement signal (i.e., in the latter half of the entire steering process), the original speed signal is input to the speed attenuation model, and the system will continue to attenuate according to a specific rule until the feedback displacement signal is equal to the command piston signal, the piston rod stops moving, and the steering process is completed.

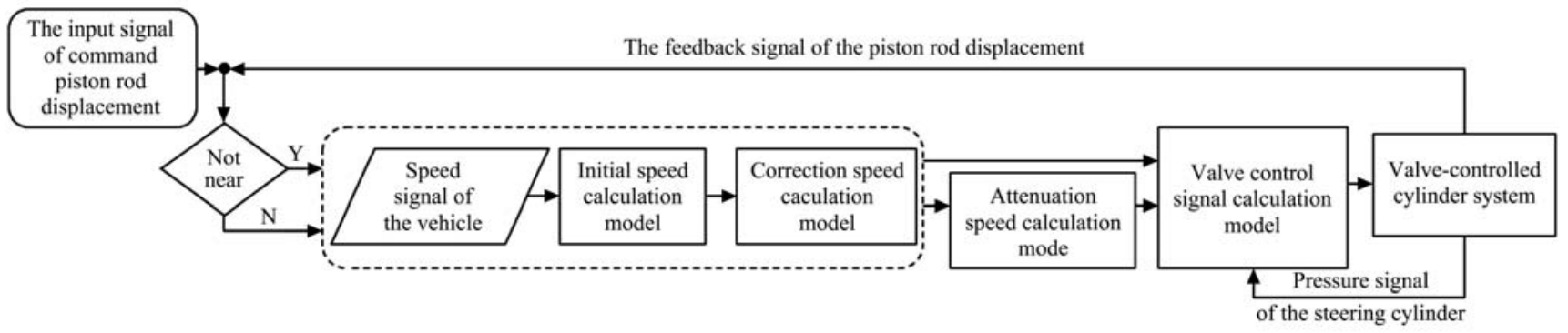

Figure 7 Compound control process of piston rod displacement/speed

\subsection{Calculation of each model}

3.3.1 Calculation of the proportional directional valve control signal

In this study, it was stipulated that the flow when the oil flows out of ports $\mathrm{A}$ and $\mathrm{B}$ of the directional valve is a positive value, and the flow when the oil flows into the oil port of the steering cylinder is a positive value. Port $\mathrm{A}$ of the valve is connected to the left chamber of the hydraulic cylinder, and port B of the valve is connected to the right chamber of the hydraulic cylinder. Ignoring leakage, Equation (11) can be obtained as

$$
Q_{A}=Q_{l}=-Q_{B}=-Q_{r}
$$

where, $Q_{A}$ is the proportional-directional valve A port flow, $\mathrm{L} / \mathrm{min} ; Q_{B}$ is the proportional-directional valve B port flow,
$\mathrm{L} / \mathrm{min} ; Q_{l}$ is the flow of the left chamber of the hydraulic cylinder, $\mathrm{L} / \mathrm{min} ; Q_{r}$ is the flow of the right chamber of the hydraulic cylinder, $\mathrm{L} / \mathrm{min}$.

The relationship between the piston rod moving speed and the flow of the left chamber of the steering cylinder is shown in Equation (12).

$$
v=\frac{Q_{l}}{A}=\frac{500}{9 \pi} Q_{l}
$$

where, $v$ is the moving speed of the steering hydraulic cylinder piston $\mathrm{rod}, \mathrm{mm} / \mathrm{s} ; A$ is the working area of the steering cylinder, $\mathrm{mm}^{2}$.

The equation used to calculate the proportional directional valve with linear flow characteristics is shown in Equation (13). 


$$
Q=Q_{N} \frac{y}{y_{N}} \sqrt{\frac{p_{s}-p_{l}}{2 \Delta p_{N}}}
$$

where, $Q$ is the real flow through the proportional-directional valve, $\mathrm{L} / \mathrm{min} ; Q_{N}$ is the rated flow of the proportional directional valve, $\mathrm{L} / \mathrm{min} ; y_{N}$ is the control signal when the valve is fully open; $y$ is the input control signal of the valve; $p_{s}$ is the output pressure of the hydraulic pump, bar; $p_{l}$ is the steering cylinder load pressure, bar; $\Delta p_{N}$ is the corresponding pressure drop of the valve at the rated flow, bar. In this study, $p_{s}=20$ bar. A Rexroth L8581B2S1 proportional directional valve is used, the rated flow $Q_{N}$ is $8 \mathrm{~L} / \mathrm{min}$, and the corresponding pressure drop $\Delta p_{N}$ is 14 bar.

The maximum load steering cylinder pressure $p_{l \max }$ can be obtained by Equation (14).

$$
p_{l \max }=\frac{F_{\max }}{A}
$$

where, $F_{\max }=1122.282 \mathrm{~N}$ per Equation (9).

Using Equations (12)-(14), the maximum speed of the hydraulic cylinder piston rod $v_{\max }=76.054 \mathrm{~mm} / \mathrm{s}$ when $p_{\text {lmax }}=11.908$ bar.

The control signal $y$ corresponding to the moving speed of the piston rod $v$ was calculated based on $y_{N}, p_{s}, p_{l}$, and $v$, as shown in Equation (15):

$$
y=\frac{9 \pi}{4000} y_{N} \sqrt{\frac{28}{p_{s}-p_{L}}} v
$$

\subsubsection{Calculation of initial piston rod speed}

The maximum vehicle speed of the agricultural chassis designed in this study is $30 \mathrm{~km} / \mathrm{h}$. In the front and middle parts of the steering process, the moving speed of the steering piston rod is related to the instantaneous vehicle speed when the steering command occurs. When the vehicle speed is 0 , the initial piston rod speed is set to $50 \mathrm{~mm} / \mathrm{s}$; when the vehicle speed is $30 \mathrm{~km} / \mathrm{h}$, the initial piston rod speed is set to $10 \mathrm{~mm} / \mathrm{s}$. The moving speed of the piston rod decreases linearly as the vehicle speed increases, as defined in Equation (16).

$$
v_{i}=50-\frac{3}{625} v_{v}
$$

where, $v_{i}$ is the initial piston rod speed, $\mathrm{mm} / \mathrm{s} ; v_{v}$ is the instantaneous vehicle speed when the steering command occurs, $\mathrm{mm} / \mathrm{s}$.

\subsubsection{Correction of initial piston rod speed}

The flow characteristic curve of the electric proportional directional valve is nonlinear. Twenty-one linearly increasing velocity signals $(10-50 \mathrm{~mm} / \mathrm{s})$ are input to the valve to obtain the real output hydraulic cylinder piston rod velocity, as shown in Figure 8 .

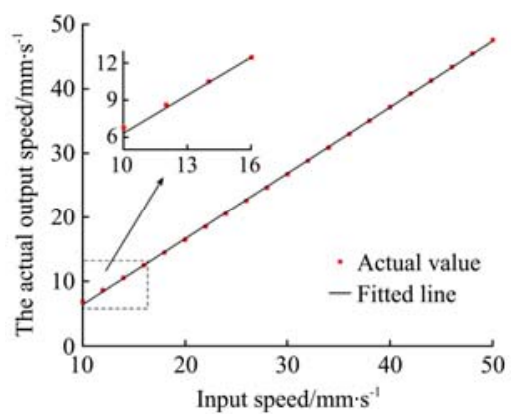

Figure 8 Input speed and real output speed

The data are linearly fitted to obtain the piston rod speed correction Equation (17):

$$
v_{c}=\frac{v_{i}+3.939}{1.026}
$$

where, $v_{c}$ is the correction speed, $\mathrm{mm} / \mathrm{s}$.

3.3.4 Attenuation of piston rod speed

When the feedback piston rod displacement signal $x$ is near the command piston rod displacement signal $x_{t}\left(x / x_{t} \geq 0.8\right)$, the speed attenuation model begins to take effect. The final calculation formula of rod speed is shown in Equation (18):

$$
v=\left\{\begin{array}{cc}
v_{c} & \left(\frac{x}{x_{t}}<0.8\right) \\
v_{c} \sqrt{5-5 \frac{x}{x_{t}}} & \left(0.8 \leq \frac{x}{x_{t}} \leq 1\right)
\end{array}\right.
$$

\section{Control system simulation analysis}

\subsection{Simulation model construction}

According to the optimized results of the steering transmission mechanism and the formulated piston rod displacement/speed joint control strategy, a simulation model is developed in AMESim software, as shown in Figure 9.

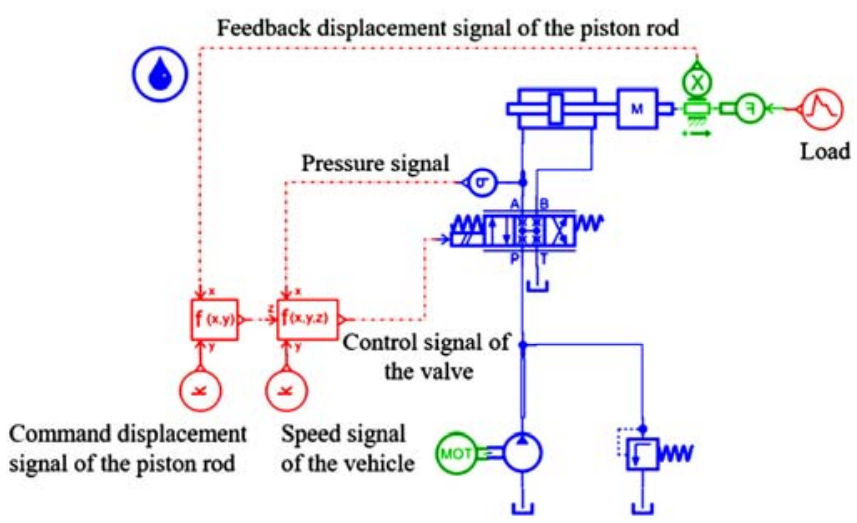

Figure 9 AMESim simulation model

Table 2 Parameters of key components in the simulation model

\begin{tabular}{clc}
\hline $\begin{array}{c}\text { Hydraulic } \\
\text { components }\end{array}$ & \multicolumn{1}{c}{ Parameter } & Index \\
\hline $\begin{array}{c}\text { Hydraulic } \\
\text { cylinder }\end{array}$ & $\begin{array}{l}\text { Piston diameter/mm } \\
\text { Rod diameter/mm } \\
\text { Length of stroke/mm }\end{array}$ & 40 \\
\hline $\begin{array}{c}\text { Three-position } \\
\text { four-way } \\
\text { proportional }\end{array}$ & $\begin{array}{l}\text { Ports P to A (B to T, P to B, and A to T) } \\
\text { characteristic flow rate at the maximum } \\
\text { opening/L·min }\end{array}$ & 20 \\
directional valve & $\begin{array}{l}\text { Ports P to A (B to T, P to B, and A to T) } \\
\text { corresponding pressure drop/bar }\end{array}$ & 150.06 \\
\hline Relief valve & Relief valve cracking pressure/bar & 14 \\
\hline
\end{tabular}

4.2 Analysis of piston rod displacement/speed when steering in situ

Figure 10 shows the time-varying curve of the displacement and speed of steering hydraulic cylinder piston rod movement from the leftmost position to the rightmost position when the unloaded vehicle is steering in situ.

Figure 10 shows that when the steering hydraulic cylinder piston rod moves from the leftmost position to the rightmost position, the real piston rod displacement and speed change curves are similar to the ideal change curve. According to the control strategy, when the vehicle is turning in situ, the ideal moving speed of the piston rod in the front and middle of the steering process is $50 \mathrm{~mm} / \mathrm{s}$. Simulation results thus show that the real moving speed is $50.29 \mathrm{~mm} / \mathrm{s}$, and the real-time for the piston rod to move $75.03 \mathrm{~mm}$ is $0.36 \mathrm{~s}$ longer than the ideal time. The maximum displacement error is $0.630 \mathrm{~mm}$, and the maximum speed error is $-3.146 \mathrm{~mm} / \mathrm{s}$. The control strategy developed in this study thus 
accomplishes joint control of the displacement and velocity of the piston rod of the hydraulic cylinder.

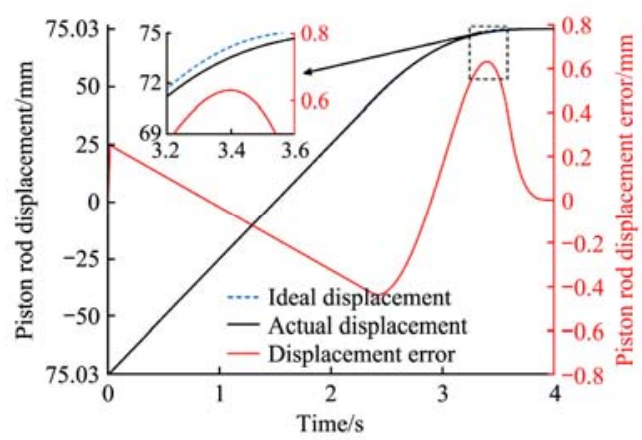

a. Piston rod displacement versus time curve

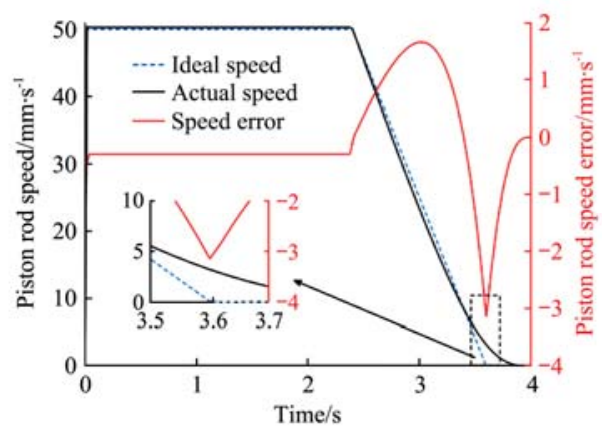

b. Piston rod speed versus time curve

Figure 10 Time-varying curve of piston rod displacement and speed when steering in situ

\subsection{Analysis of piston rod displacement/speed when steering with different loads}

Figure 11 shows that when the vehicle speed is $15 \mathrm{~km} / \mathrm{h}$, under no-load and full-load conditions, the steering resistance is $872.886 \mathrm{~N}$ at no load, and the steering resistance is $1122.282 \mathrm{~N}$ at full load. The time-varying curve of the displacement and speed of the steering hydraulic cylinder piston rod moves from the neutral position to the rightmost position.

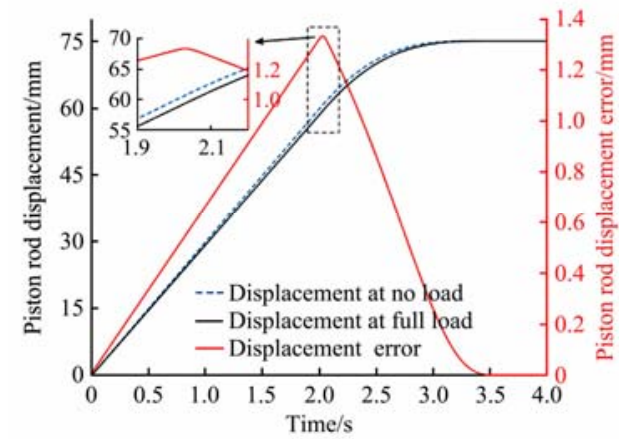

a. Piston rod displacement versus time curve

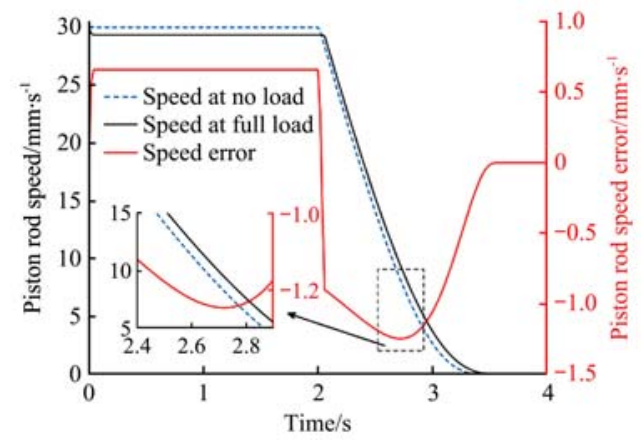

b. Piston rod speed versus time curve

Figure 11 Time-varying curve of piston rod displacement and speed when steering with different loads
Figure 11 shows that when the vehicle speeds are the same, the difference in vehicle load will only marginally affect the piston rod displacement and speed changes. For example, when the vehicle is turning at $15 \mathrm{~km} / \mathrm{h}$, the ideal moving speed of the piston rod in the front and middle of the steering process is $30 \mathrm{~mm} / \mathrm{s}$. Simulation results thus show that the actual moving speed is $29.97 \mathrm{~mm} / \mathrm{s}$ at no load and $29.32 \mathrm{~mm} / \mathrm{s}$ at full load. The full-load steering process takes $0.12 \mathrm{~s}$ longer than the no-load steering process. The change in steering load thus has almost no effect on the formulated steer-by-wire system.

\subsection{Analysis of piston rod displacement/speed when steering} at different vehicle speeds

Figure 12 shows the time-varying curve of the displacement and speed of the steering hydraulic cylinder piston rod from the neutral position to the rightmost position at vehicle speeds of 0 , $6 \mathrm{~km} / \mathrm{h}, 12 \mathrm{~km} / \mathrm{h}, 18 \mathrm{~km} / \mathrm{h}, 24 \mathrm{~km} / \mathrm{h}$, and $30 \mathrm{~km} / \mathrm{h}$.

When steering at different vehicle speeds, the piston rod speed in the front and middle parts of the steering process follows the expected rod speed. According to the control strategy, when the vehicle is turning at speeds of $0,6 \mathrm{~km} / \mathrm{h}, 12 \mathrm{~km} / \mathrm{h}, 18 \mathrm{~km} / \mathrm{h}$, $24 \mathrm{~km} / \mathrm{h}$, and $30 \mathrm{~km} / \mathrm{h}$, the ideal moving speeds of the piston rod in the front and middle of the steering process are $50 \mathrm{~mm} / \mathrm{s}, 42 \mathrm{~mm} / \mathrm{s}$, $34 \mathrm{~mm} / \mathrm{s}, 26 \mathrm{~mm} / \mathrm{s}, 18 \mathrm{~mm} / \mathrm{s}$, and $10 \mathrm{~mm} / \mathrm{s}$, respectively. Simulation results show that the real moving speeds are $50.29 \mathrm{~mm} / \mathrm{s}, 42.17 \mathrm{~mm} / \mathrm{s}, 34.04 \mathrm{~mm} / \mathrm{s}, 25.92 \mathrm{~mm} / \mathrm{s}, 17.88 \mathrm{~mm} / \mathrm{s}$, and $10.13 \mathrm{~mm} / \mathrm{s}$, respectively. The developed steer-by-wire system thus meets the requirements of fast steering at low vehicle speed and slow steering at high vehicle speed.

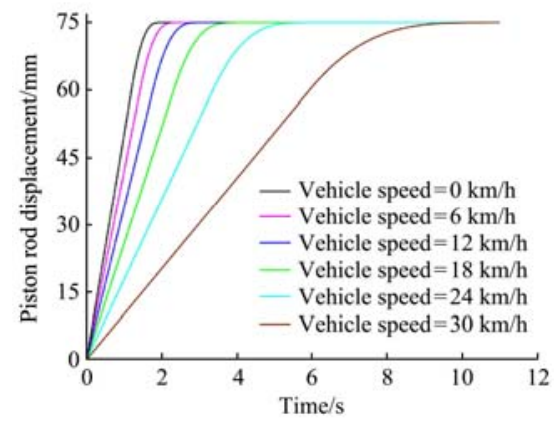

a. Piston rod displacement versus time curve

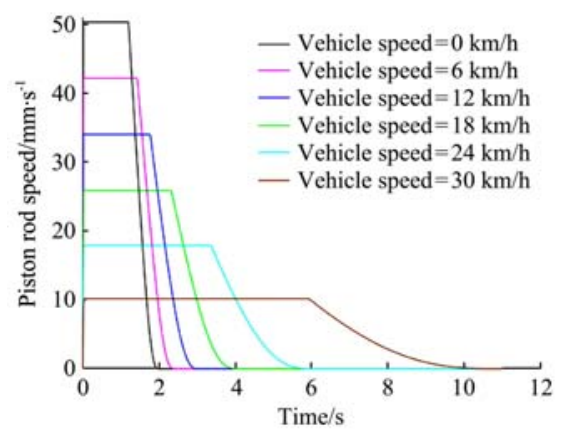

b. Piston rod speed versus time curve

Figure 12 Time-varying curve of piston rod displacement and speed when steering at different vehicle speeds

Table 3 Horizontal and vertical displacement of the right wheel center

\begin{tabular}{cccc}
\hline $\begin{array}{c}\text { Piston rod displacement } \\
\text { command } / \mathrm{mm}\end{array}$ & $\begin{array}{c}\text { Vehicle speed } \\
/ \mathrm{km} \cdot \mathrm{h}^{-1}\end{array}$ & $\begin{array}{c}\text { Horizontal } \\
\text { displacement } / \mathrm{mm}\end{array}$ & $\begin{array}{c}\text { Vertical } \\
\text { displacement } / \mathrm{mm}\end{array}$ \\
\hline \multirow{2}{*}{30} & 6 & 197.45 & 1550.46 \\
70 & 15 & 729.76 & 5605.99 \\
\hline \multirow{2}{*}{70} & 6 & 1028.19 & 3385.91 \\
& 15 & 3709.90 & 12074.57 \\
\hline
\end{tabular}




\subsection{Analysis of steering trajectory}

The above analysis shows that when the piston rod displacement command is given, the change in the steering angle of the wheel with time is known so that the steering trajectory of the vehicle can be further obtained. Figure 13 and Table 3 show that when the vehicle is traveling at speeds of $6 \mathrm{~km} / \mathrm{h}$ and $15 \mathrm{~km} / \mathrm{h}$, the given piston rod displacement commands are $30 \mathrm{~mm}$ and $70 \mathrm{~mm}$ to the right, respectively, and the horizontal and vertical displacement of the right wheel center changes during the steering process. Assuming that the vehicle goes straight in the vertical direction before turning, the origin is the center position of the right wheel when the steering command is executed, and the speed of the right wheel remains unchanged during the turning process.

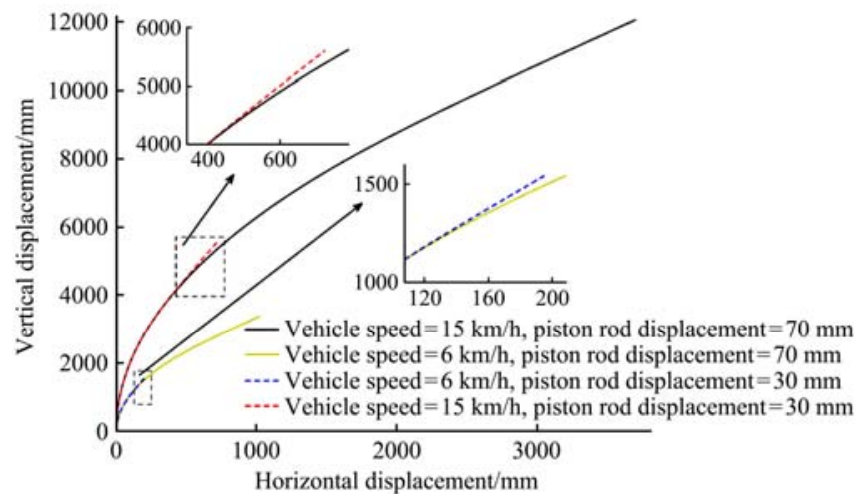

Figure 13 Horizontal and vertical displacement of the right wheel center

The instantaneous speed during steering determines the general trend of vehicle trajectory change during steering, which, together with the piston rod displacement, determines the vehicle position at the end of the steering process. In a real automatic steering system, the corresponding vehicle speed and piston rod command displacement during steering can be formulated according to the target steering path of the vehicle.

\section{Conclusions}

1) Parameter optimization for the designed agricultural chassis steering transmission mechanism is performed. The relationship between the inner wheel steering angle $\alpha$ and the outer wheel steering angle $\beta$ is also derived. The optimal value of the spacing between the piston rod holes of the steering cylinder $l$ is also determined to be $925 \mathrm{~mm}$. The size of the steering hydraulic cylinder is calculated. The rod diameter, piston diameter, and length of stroke are $20.00 \mathrm{~mm}, 40.00 \mathrm{~mm}$, and $150.06 \mathrm{~mm}$, respectively.

2) To control the steering angle and the steering angular velocity of the wheel, the compound control strategy of the displacement and speed of the steering hydraulic cylinder piston rod in the steer-by-wire system was formulated.

3) The AMESim simulation model is developed to analyze the steering characteristics at different loads and different vehicle speeds. The results show that the developed steer-by-wire system meets the requirements of fast steering at low vehicle speed and slow steering at high vehicle speed.

\section{Acknowledgements}

This work was financially supported by the State Key Research Program of China (Grant No. 2021YFD2000105) and the Scientific Research and Agricultural Technology Promotion Project of Guangdong Provincial Department of Agriculture and Rural Affairs (Grant No. 2021125).
The authors also acknowledge the editors and the anonymous reviewers for their critical comments and suggestions for improving the manuscript.

\section{[References]}

[1] Song S J, Li Y, Qu J W, Zhou W, Guo K Q. Design and test of flexible chassis automatic tracking steering system. Int J Agric \& Biol Eng, 2017; 10(5): 45-54.

[2] Wang $\mathrm{H}$, Noguchi N. Adaptive turning control for an agricultural robot tractor. Int J Agric \& Biol Eng, 2018; 11(6): 113-119.

[3] Gat G, Gan-Mor S, Degani A. Stable and robust vehicle steering control using an overhead guide in greenhouse tasks. Comput Electron Agric, 2016; 121: 234-244.

[4] Wang J, Zhu Y T, Chen Z B, Yang L L, Wu C C. Auto-steering based precise coordination method for in-field multi-operation of farm machinery. Int J Agric \& Biol Eng, 2018; 11(5): 174-181.

[5] Lu Z X, Diao X Y, Gong J H, Wu J G, Zhong W J. Assessment and characteristic of road-feeling for wheeled tractor hydraulic steer-by-wire system. Transactions of the CSAE, 2015; 31(12): 57-63. (in Chinese)

[6] Liu J Y, Tan J Q, Mao E R, Song Z H, Zhu Z X. Proportional directional valve based automatic steering system for tractors. Front Inform Technol \& Elect Eng, 2016; 17(5): 458-464.

[7] Daher N, Ivantysynova M. Yaw stability control of articulated frame off-highway vehicles via displacement controlled steer-by-wire. Control Eng Practice, 2015; 45: 46-53.

[8] Zhang G Q, Zhu S H, Li W H, Chen X Q, Chen Q. Simulation and experiment of steering by wire system of large wheel tractor with hinge swing link. Transactions of the CSAM, 2014; 45(2): 28-33. (in Chinese)

[9] Zong C F, Li G, Zheng H Y, He G, Zhang Z X. Study progress and outlook of chassis control technology for $\mathrm{x}$-by-wire automobile. China Journal of Highway and Transport, 2013; 26(2): 160-176. (in Chinese)

[10] Wang X Y, Yang J, Quan L, Zhang X G, Wang J. A novel high-efficiency wheel loader power steering system with fault-tolerant capability. IEEE Trans Veh Technol, 2018; 67(10): 9273-9283.

[11] Wu X D, Li W Q. Variable steering ratio control of steer-by-wire vehicle to improve handling performance. Proc Inst Mech Eng Part D-J Automob Eng, 2020; 234(2): 774-782.

[12] Bai Y H, Quan L. Control strategy of the electro-hydraulic position and speed hybrid servo system. Journal of Mechanical Engineering, 2010; 46(24): 150-155.

[13] Sleesongsom S, Bureerat S. Multiobjective optimization of a steering linkage. J Mech Sci \& Technol, 2016; 30: 3681-3691.

[14] Meng G Y, Sheng K M, Huang J X, Meng X, Shi Y X. Optimal design on steering mechanism for crossing and variable wheel-track vehicles. Chinese Journal of Construction Machinery, 2016; 14(6): 504-507. (in Chinese)

[15] Ren W T, Chi D X, Liu J B, Wei D Y, Yu X Z, Che Z. Design and test on remote rice transplanter automatic steering system. Transactions of the CSAM, 2012; 43(1): 175-179. (in Chinese)

[16] Yin X, Liu G H, Yang T X, Jin C Q. Development of an automatic steering system for a rice transplanter. Journal of Agricultural Mechanization Research, 2019; 41(1): 153-157. (in Chinese)

[17] Yin X, Du J, Noguchi N, Yang T X, Jin C Q. Development of autonomous navigation system for rice transplanter. Int J Agric \& Biol Eng, 2018; 11(6): 89-94.

[18] Lu Z X, Gong J H, Lu Y, Diao X Y, Cheng Z, Jiang C X, et al. Simulation and experiment of dual channel PID control for hydraulic steer-by-wire system of tractor. Transactions of the CASE, 2016; 32(6): 101-106. (in Chinese)

[19] Fang S S, Lu Z X, Wang Z C, Diao X Y, Lu Y, Gong J H, et al. Design and prototype performance experiments of steering-by-wire hydraulic pressure system of tractor. Transactions of the CASE, 2017; 33(10): 86-93. (in Chinese)

[20] Zong C F, Han Y D, He L, Wang X. Research on variable angle transmission ratio characteristics for automobile with SBW. China Journal of Highway and Transport, 2015; 28(9): 115-120. (in Chinese)

[21] Liu P Y, Wang Z J, Li H T, Song Y J, Wei W J, Zhang S Y. Design of steering mechanism with adjustable wheel track. Journal of Agricultural Mechanization Research, 2015; 46(6): 44-48, 120. (in Chinese)

[22] Jiang L B, Liu J X, Cheng C. Optimization design of mining dump truck steering mechanism based on orthogonal test. China Mechanical Engineering, 2013; 24(15): 2036-2041. (in Chinese) 